\title{
STUDENT-BASED EXAMPLES: DO THEY HELP OR HINDER INSTRUCTION?
}

\author{
Cathy A. Enz \\ Indiana University
}

Many professors, myself included, have for years operated under the impression that examples from the current experiences of students' lives are helpful, useful and relevant for illustrating complex ideas or theories. We seek to use examples from the students' realm of experience. We discuss conflict and perceptions in the context of roommate interactions. The university's procedures and goals are presented as a foil for discussions of organizational designs, bureaucracy, and goal setting. We rely on the football and basketball teams for discussions of leadership and cooperation. The experiences of job interviews are used to discuss corporate culture and socialization. Finally, we bring home the nuances of performance appraisal, feedback and reward structures by discussing the operation of the very class we teach.

We rarely stop to consider the usefulness of a course filled with illustrations and examples from the students' world and the university setting. Do examples grounded in the students' own experiences help or hinder their understanding of organizations and organizational behavior? By attempting to make the subject relevant, have we simplified its application, trivialized its importance, or left the student ignorant of "real world" settings?

Consider the possibility that we insult and bore our students with examples based on what we think are their own experiences. Unwittingly we may be talking down to our students, suggesting by these simple illustrations that they cannot understand the subject if we apply it to the focal setting, i.e., a business. We bore them because the example is self-evident and doesn't challenge them to envision themselves in the role of the manager. We limit their imaginations by giving them examples that are too clear and too easy to visualize. We may also open ourselves to criticism that the material is obvious, already known, common-sense, or lacking in support from the real world.

A personal experience recently brought the drawbacks of student-based examples home to me. I teach large sections (600 students) of an introductory organizational behavior (OB) course for undergraduates. On one occasion I requested experts from our instructional resource facility to observe my class. After watching my students listen to me for two class periods they observed that the students appeared restless when I illustrated a point with an example close to their own experiences. In contrast, when I used a large Fortune 500 company with which I had personal contact as the basis of an example, the students sat in hushed 
silence. Clearly they were fascinated by the "real" company and bored by their own situation. While this observation may seem obvious, it had not occurred to me that the examples drawn from the students' lives would elicit disinterest or negative reactions.

One possible recommendation for instruction based on this experience is to develop non-university organizational illustrations versus student-based personal examples in our OB courses. Lest we rush off to begin a healthy revision of our examples, however, let me muddy the waters a bit. My helpful educational colleagues have made one additional observation. They observed that of the many business-derived examples I use in class, the big business examples captivated the students while the small business illustrations failed to keep them on the edge of their seats. This observation, offered with the intent of objective helpfulness, was not so graciously received; I found it to be credible, but also disconcerting. I was troubled that some examples may overshadow the content they are designed to highlight.

My students are captivated by the imagery of big, powerful, sexy corporations. If my goal is to keep them excited, then the clear action would be to focus examples on these large appealing corporations. If I choose to do this, will I be pandering to the students? At what point do examples become a form of entertainment versus learning? Is entertainment wrong? Do the students learn more or less from this approach?

My own resolution of the student-based example problem is to replace many of my student examples with organizational illustrations. I cannot, however, part with the applications drawn from a variety of different types of organizations, and have thus resigned myself to occasionally boring my students. 